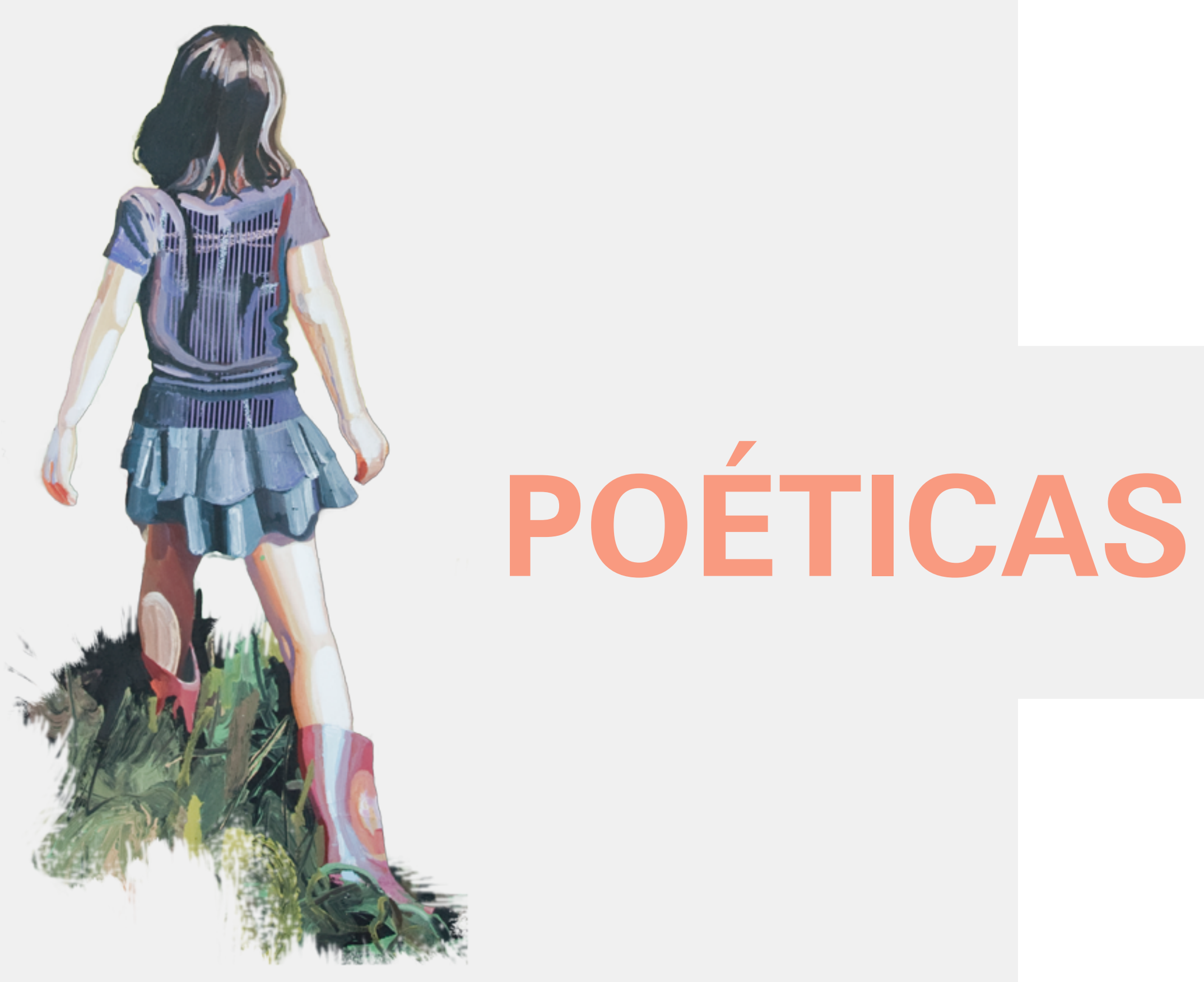




\section{PINTURA A FORA}

Leonora Weissmann* $\quad$ * Atua profissionalmente como artista plástica, designer e cantoUniversidade Federal de Minas Gerais, onde também possui título de Mestre em Artes. www.leonoraweissmann.org 


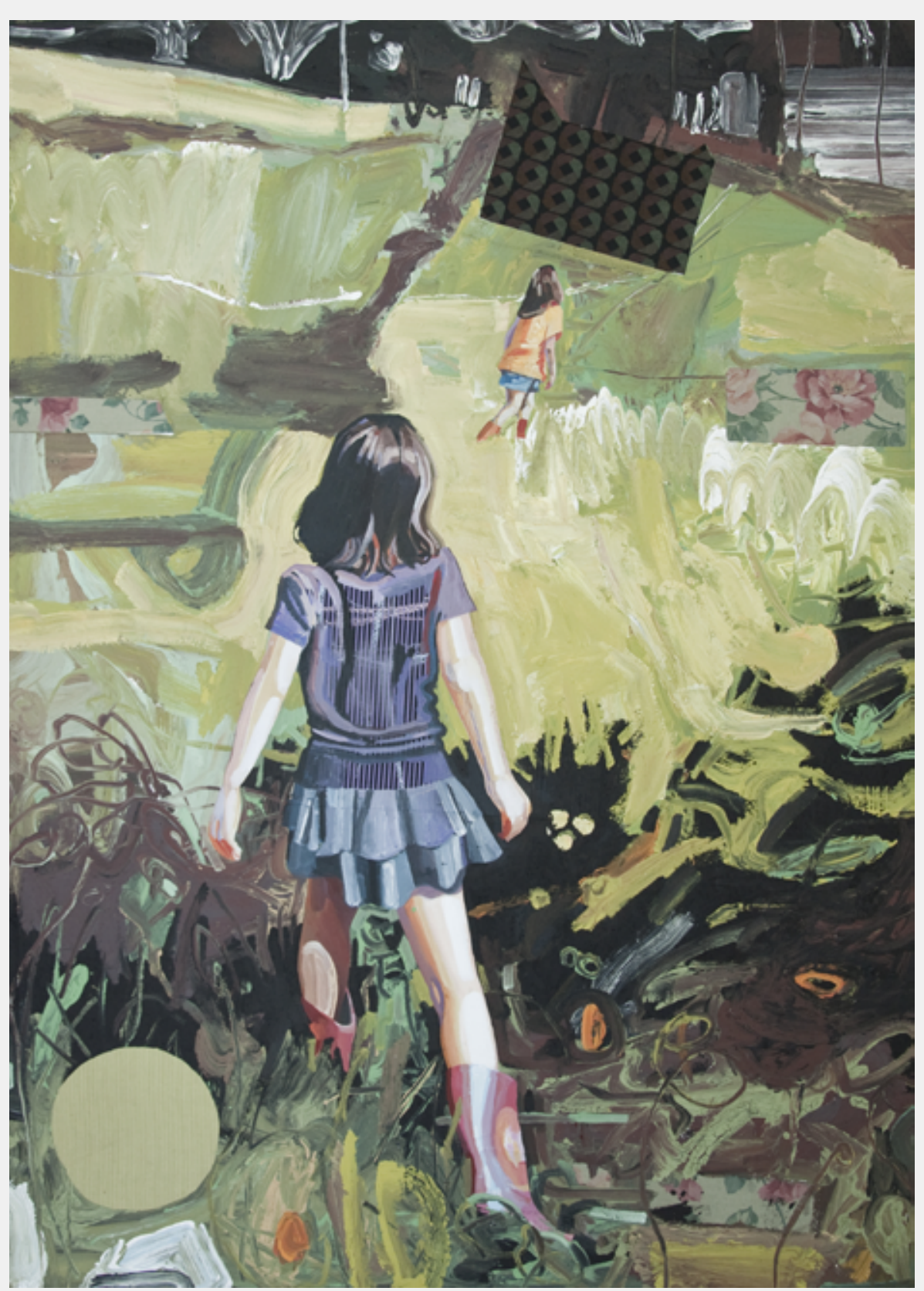

Boi da cara preta

Acrílica, vinílica e colagem sobre tela $180 \times 130 \mathrm{~cm}$ 


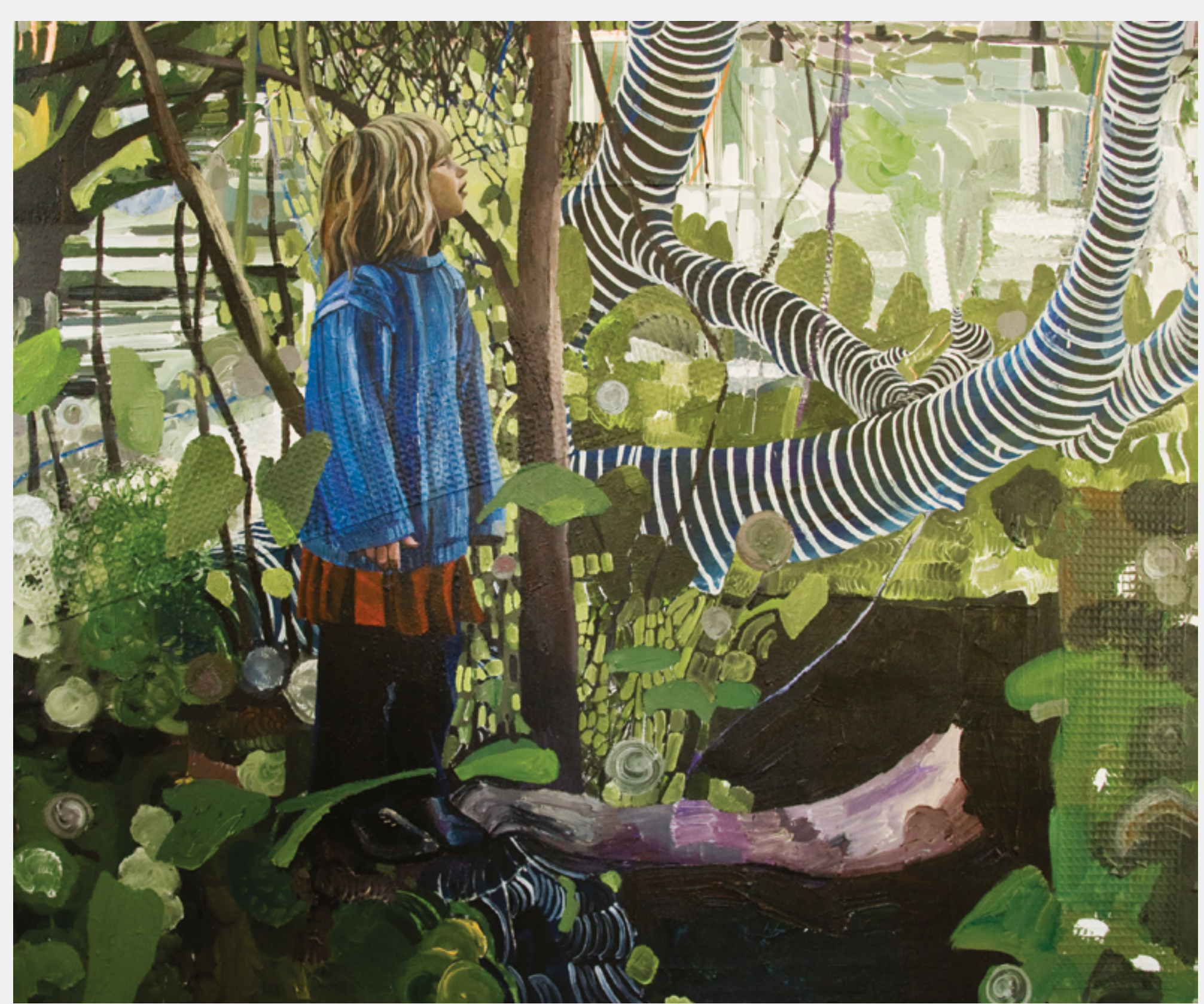

Onde está você?

Acrílica, vinílica e colagem sobre tela $150 \times 200 \mathrm{~cm}$ 


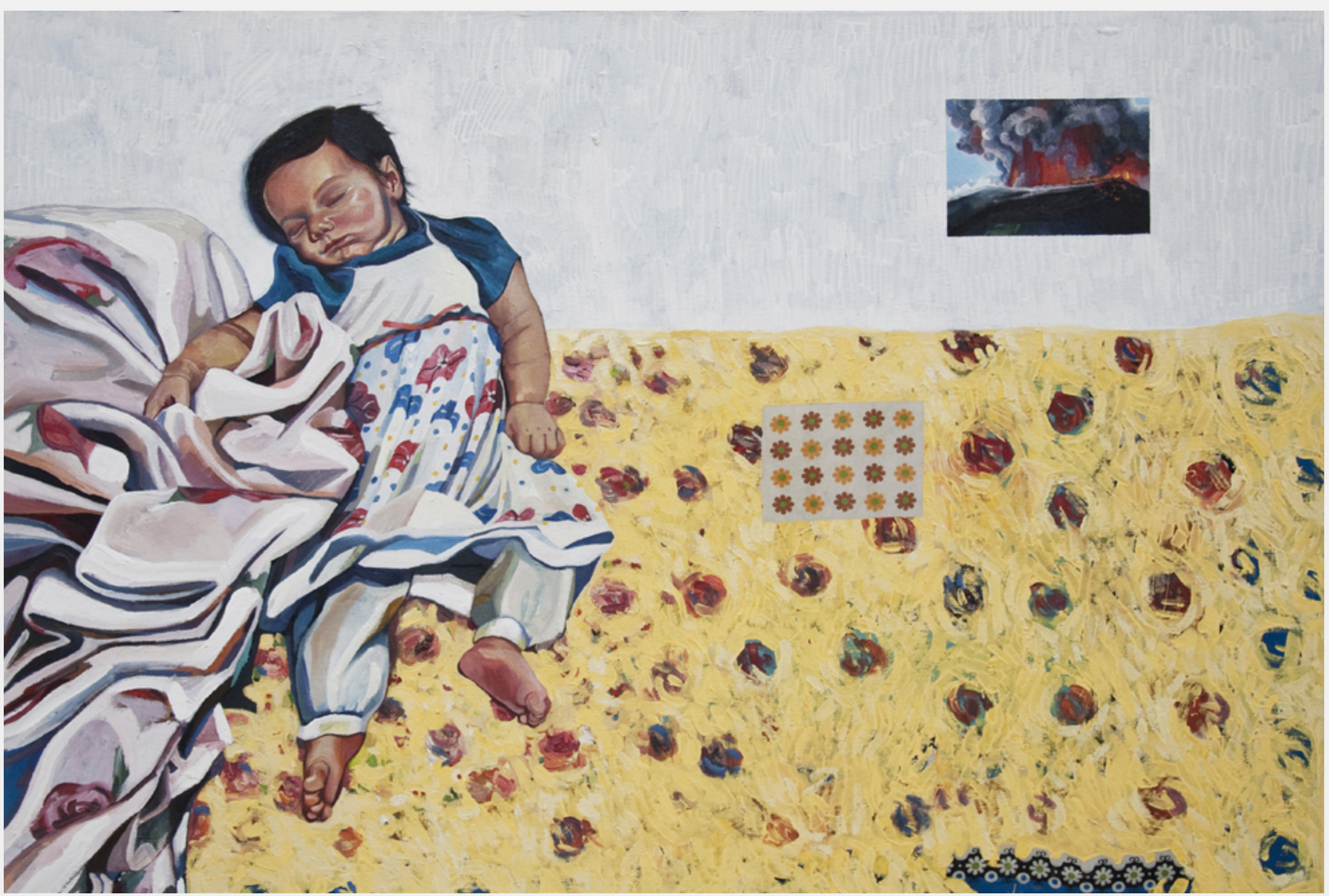

Isadora e o vulcão

Acrílica e colagem sobre tela $100 \times 150 \mathrm{~cm}$ 


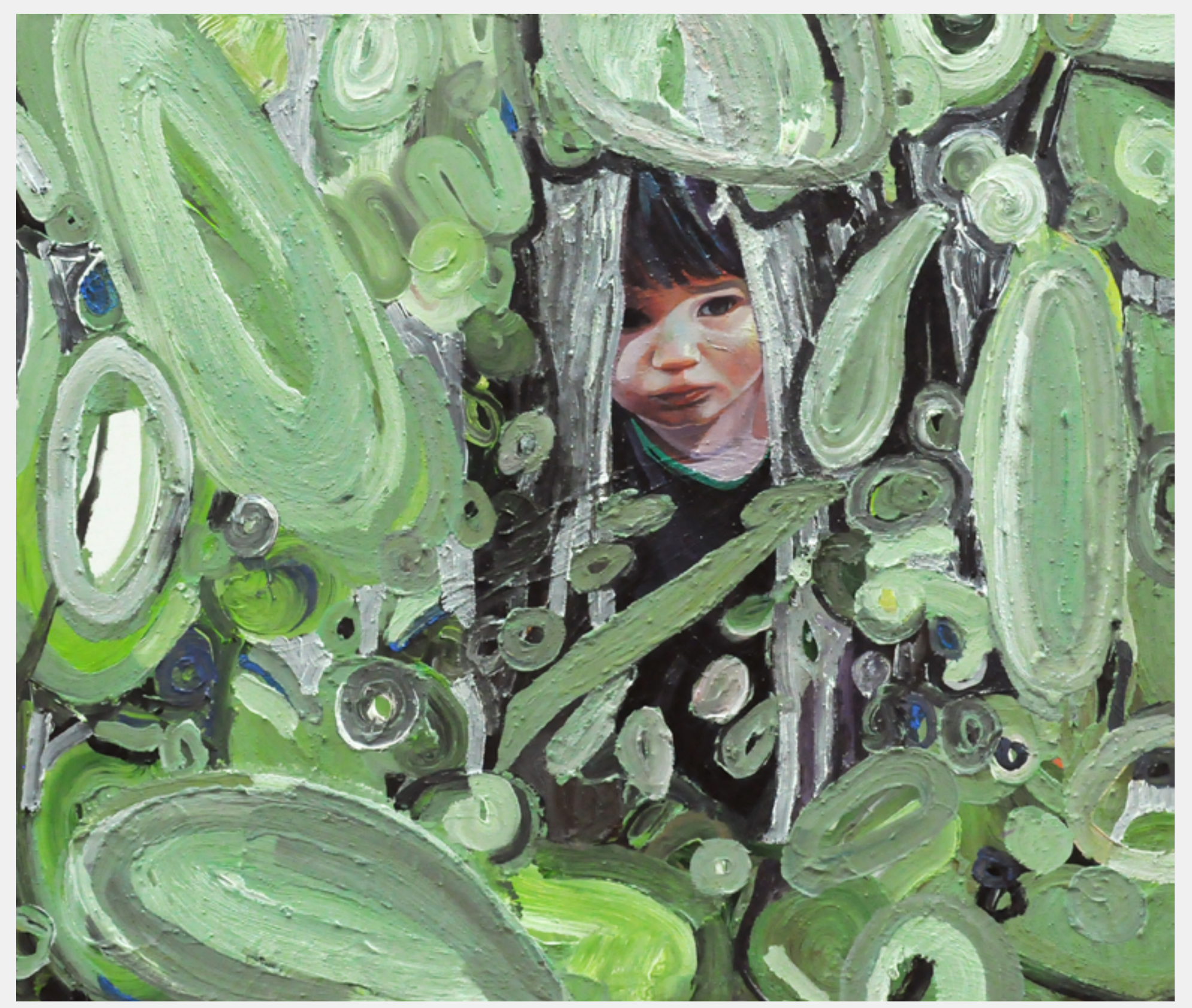

Medo de Ser

Acrílica, vinílica e colagem sobre tela $80 \times 100 \mathrm{~cm}$ 


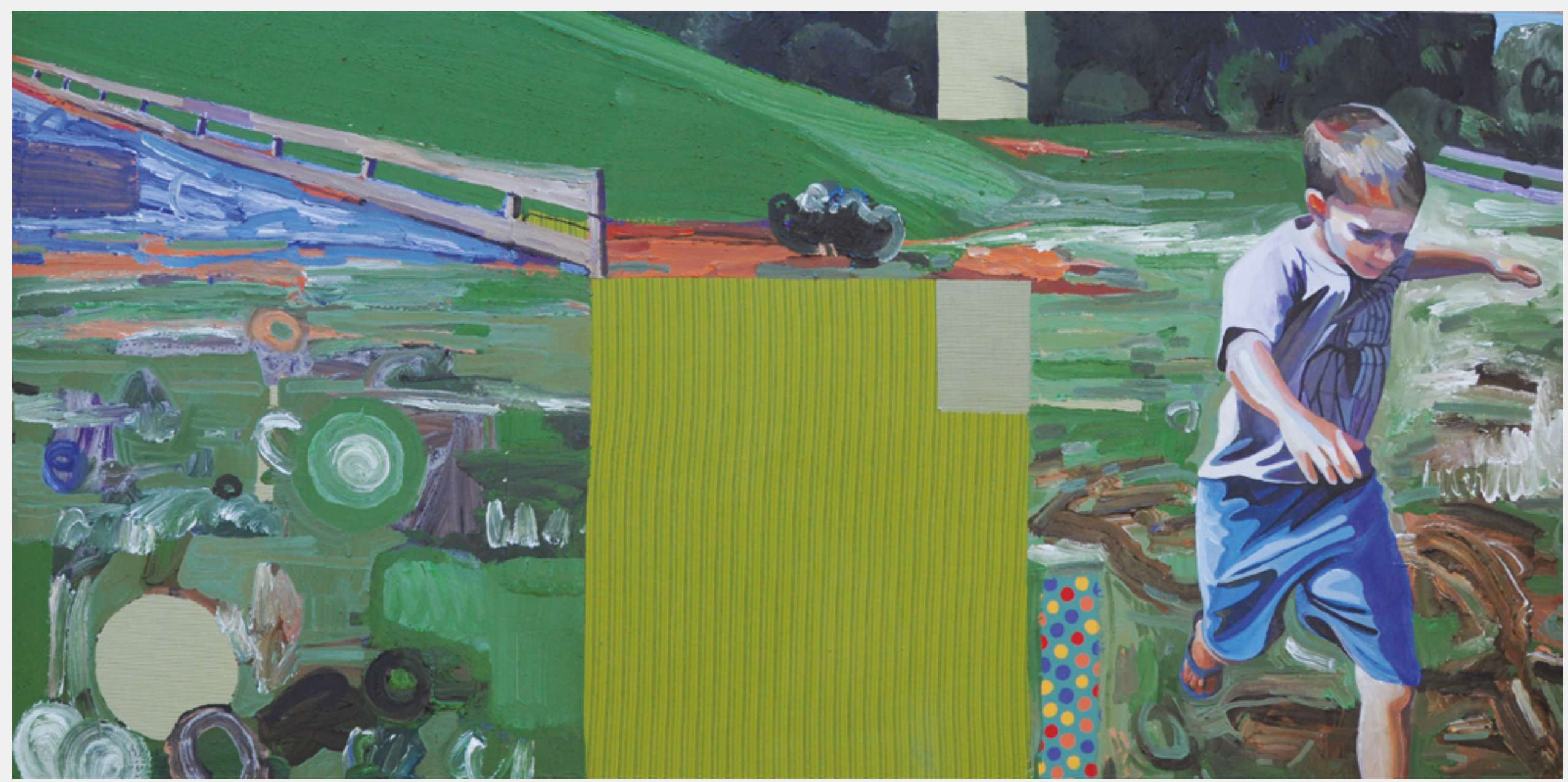

Pintura a fora

Acrílica, vinílica e colagem sobre tela $100 \times 200 \mathrm{~cm}$ 


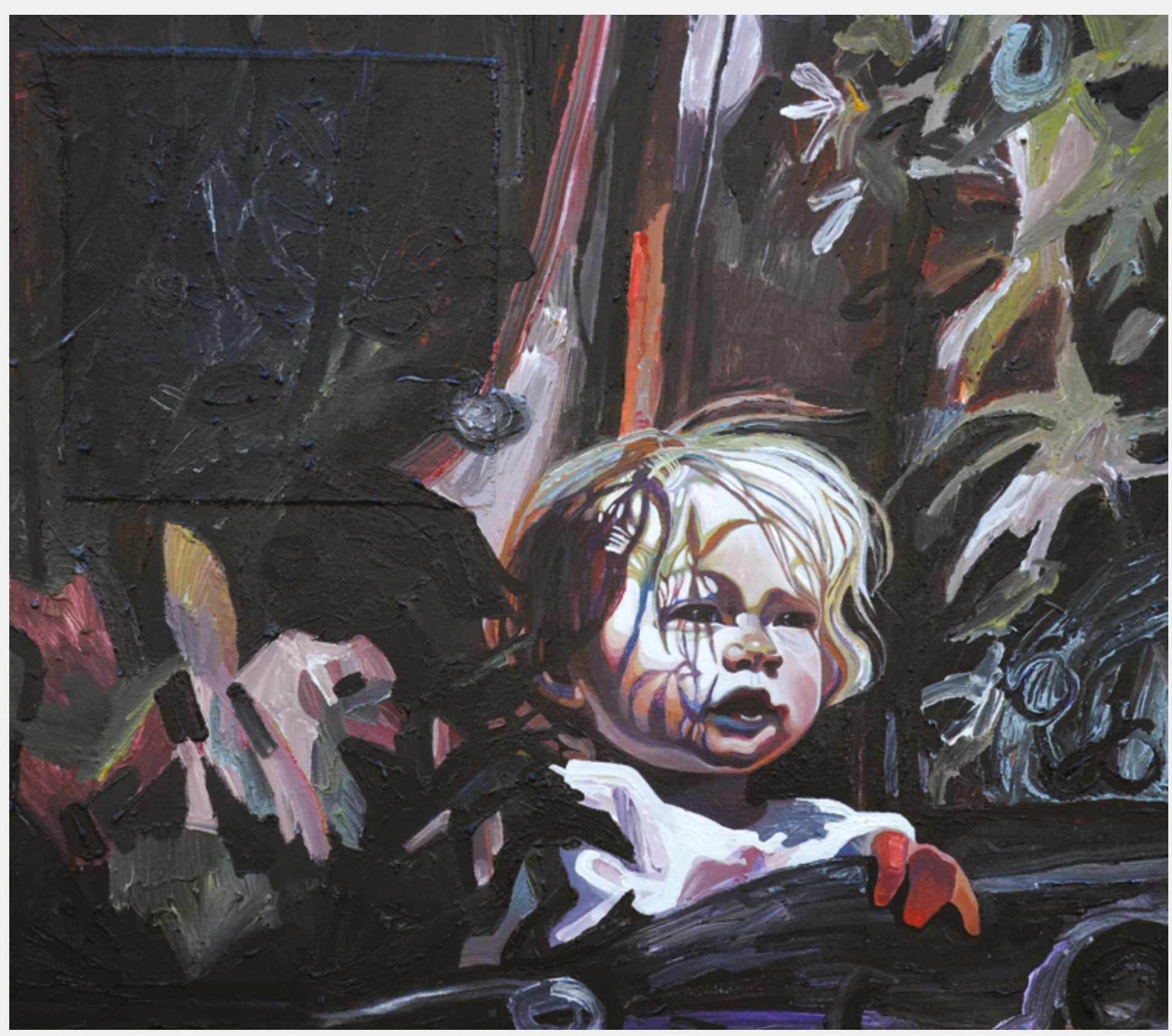

Toca

Acrilica, vinilica e colagem sobre tela $80 \times 100 \mathrm{~cm}$ 